\title{
Subcutaneous emphysema and pneumomediastinum in child with asthma revealing occult foreign body aspiration: a case report
}

\author{
Mounir Bourrous ${ }^{1 *}$, Widad Lahmini ${ }^{1}$, Hassan Nouri $^{2}$ and Nouzha Haimeur ${ }^{3}$
}

\begin{abstract}
Background: Exacerbations of asthma constitute the most common cause of pneumomediastinum and subcutaneous emphysema in children. Foreign body aspiration is a rare cause of pneumomediastinum and subcutaneous emphysema. Foreign body aspiration leading to the occurrence of pneumomediastinum in a child with asthma may go unnoticed and be wrongly attributed to asthma, which leads to delayed diagnosis as well as to life-threatening and long-term complications.

Case presentation: We describe a case of a 6-year-old Moroccan boy with asthma who was admitted to our emergency department for acute dyspnea and persistent dry cough. The patient was initially treated as having acute asthma exacerbation. Owing to insufficient clinical and radiographic improvement with asthma treatment, a rigid bronchoscopy under general anesthesia was performed. A pumpkin seed was removed from the left main bronchus. Clinical and radiographic improvement was achieved after foreign body extraction.

Conclusions: This case emphasizes that the possibility of foreign body aspiration should always and carefully be considered by the emergency physician when faced with a child with asthma presenting with pneumomediastinum and subcutaneous emphysema as an important differential diagnosis even in the absence of a history of foreign body aspiration.
\end{abstract}

Keywords: Foreign body aspiration, Child, Pneumomediastinum, Subcutaneous emphysema

\section{Introduction}

Pneumomediastinum (PM) is defined as the presence of free air in the mediastinum. Caused by a perforation of the tracheobronchial tree, it occurs in any condition that creates a gradient between intra-alveolar and perivascular interstitial pressures. Subcutaneous emphysema (SCE) results when air dissects along planes of the mediastinum to the subcutaneous tissues of the thorax, neck, and upper limbs. PM rarely occurs in children and is generally a benign entity that requires supportive care $[1,2]$. The most common cause of PM in children is exacerbations of asthma [1-3]. PM and SCE are rare presentations of foreign

\footnotetext{
* Correspondence: mounirbourrous@yahoo.fr

'Department of Paediatric Emergency, UHC Mohamed VI, Cadi Ayyad University, Faculty of medicine and pharmacy, PO Box: 7010, Sidi Abbad Street, 40000 Marrakech, Morocco

Full list of author information is available at the end of the article
}

body (FB) aspiration. In this report, we describe a case of a child with asthma who presented with PM and SCE, which were treated initially as an exacerbation of asthma and later found to be induced by FB aspiration. This case emphasizes the difficulties encountered during the diagnosis of FB aspiration in patients with asthma exacerbation. In fact, FB aspiration leading to the occurrence of a PM in a child with asthma may go unnoticed and be wrongly attributed to asthma, which leads to delayed diagnosis as well as life-threatening and long-term complications.

\section{Case presentation}

A 6-year-old Moroccan boy with asthma was admitted to our emergency department because of acute dyspnea and persistent dry cough. Two days prior to his admission, he had fever, cough, and wheezing. He was initially treated 
with oral antibiotics (azithromycin $10 \mathrm{mg} / \mathrm{kg} /$ day) and nebulized salbutamol at his pediatrician's office. However, owing to the worsening of his condition and the appearance of cervical swelling, he was referred to our department. Since age 3 years, the child had been diagnosed with intermittent asthma, had been well-monitored, and had been placed on outpatient treatment. Viral triggers were common with this patient. His family had an average socioeconomic level. Their home was airy and sunny without any pets. There was not any exposure to smoke from tobacco. The child had no particular pathological history. He had never been hospitalized for a severe crisis. He had nonfrequent recurrent wheezing episodes that occurred three to four times per year and were treated with bronchodilators and oral steroids when necessary. There was no family history of atopy. According to the parents, the patient had no history of food allergy, trauma, choking episode, FB aspiration, or any recent viral infection triggers for an acute asthma exacerbation. His physical examination showed the following: respiratory distress with perioral cyanosis, tachypnea (respiratory rate, $46 / \mathrm{min}$ ) and hypoxia (oxygen saturation, $84 \%$ in room air), bilateral wheezing, and a cervical swelling with crepitations on the neck. His temperature was $38.3^{\circ} \mathrm{C}$. His hemodynamic state was stable (pulse rate, 110 beats/minute; blood pressure, $100 / 60 \mathrm{mmHg}$ ). The patient was conscious. The result of his neurological examination was normal. A chest $x$-ray showed SCE, PM, bilateral hyperinflation, and absence of radio-opaque FB (Fig. 1). The laboratory tests showed the following values: white blood cell count 17,000 cells $/ \mu \mathrm{l}$, hemoglobin $11.5 \mathrm{mg} / \mathrm{dl}$, platelet count $220,000 / \mu \mathrm{l}$, C-reactive protein $38 \mathrm{mg} / \mathrm{L}$, urea $15 \mathrm{mg} / \mathrm{dl}$, creatinine 0.8 $\mathrm{mg} / \mathrm{dl}$, and prothrombin time $100 \%$. The boy was initially treated as having an acute asthma exacerbation complicated by PM and was administered oxygen, intravenous steroids (hydrocortisone $5 \mathrm{mg} / \mathrm{kg} / 6 \mathrm{~h}$ ), nebulized salbutamol, and amoxicillin-clavulanic acid $(100 \mathrm{mg} / \mathrm{kg} /$ day). The evolution was made worse by respiratory distress (increase of respiratory rate at $54 / \mathrm{min}$, decrease of oxygen saturation at $78 \%$ in room air) and extension of swelling that progressed from the neck to the face and shoulders. Owing to insufficient clinical and radiographic improvement under the appropriate treatment, the possibility of a differential diagnosis, especially that of FB aspiration, was considered. Thus, a rigid bronchoscopy (size 5.0) was performed under general anesthesia on the second day, which showed the FB (pumpkin seed) located at the entry of the right main bronchus (Fig. 2). After removal of the FB, a complete resolution of clinical signs was observed. The child was discharged to home the next day and was placed on outpatient treatment. Radiographic control after 10 days showed complete recovery. The evolution was normal after 2 years of follow-up with two asthma attacks treated on an outpatient basis with nebulized salbutamol.

\section{Discussion}

This case report describes a 6-year-old boy who was admitted to our emergency department for acute dyspnea and persistent dry cough. On the basis of his past medical history of intermittent asthma, his physical examination, and results of his chest $\mathrm{x}$-ray, the patient was initially treated as having an acute asthma exacerbation complicated by PM. Owing to insufficient clinical and radiographic improvement under the appropriate treatment,

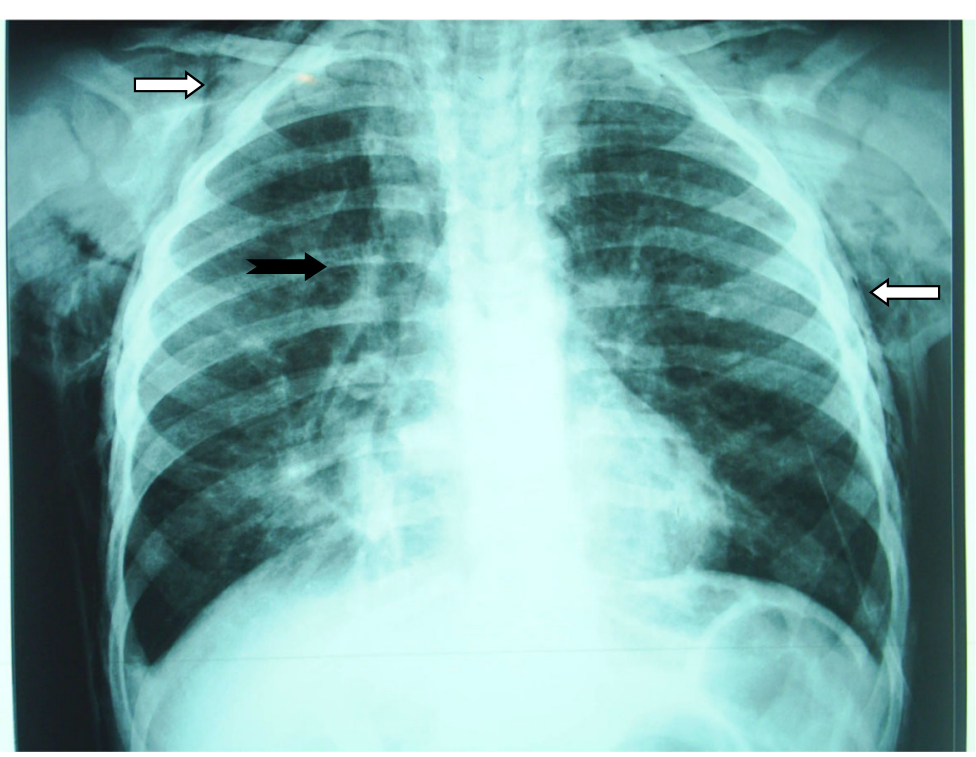

Fig. 1 Radiograph of the chest showing subcutaneous emphysema (white arrows) and pneumomediastinum (black arrow), right basal pneumonia, and bilateral hyperinflation of the lung 


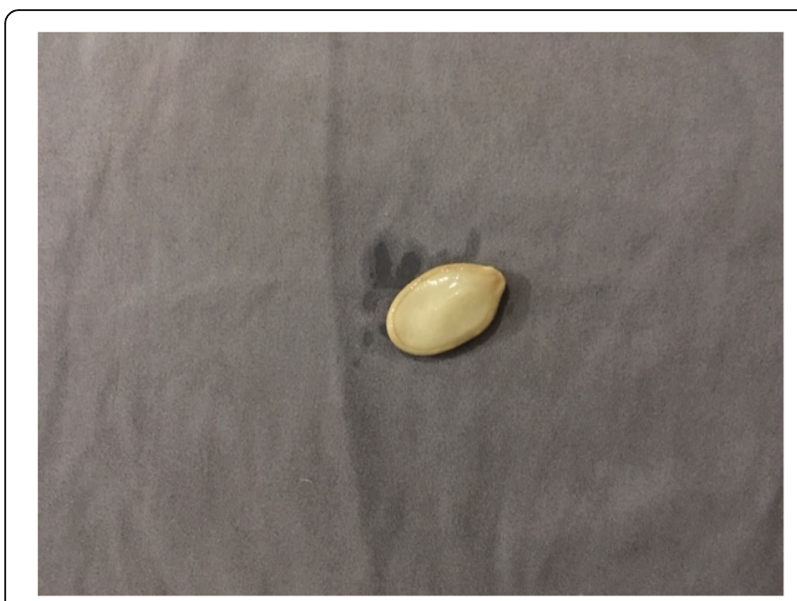

Fig. 2 Foreign body (pumpkin seed) removed

however, the possibility of a differential diagnosis, especially that of $\mathrm{FB}$ aspiration, was considered. A rigid bronchoscopy was performed, which showed an FB located at the right main bronchus. Our patient was younger (about 6 years old) than other patients in the literature, and no history of FB aspiration was reported.

SPM has been reported both as a consequence of an asthma exacerbation and as a sign of a first asthma attack in children. SPM may be associated with poorly controlled asthma. A majority of cases appear to occur in teenagers, and no obvious differences in incidence have been reported between the sexes [4]. Our patient was well controlled for intermittent asthma without any notable events. History taking, physical examination, and standard chest $\mathrm{x}$-ray are most often diagnostic, and there is rarely a need for other investigation. Chest $\mathrm{x}$-ray provides the right diagnosis in almost all cases $[4,5]$.

PM and SCE due to FB aspiration is a rare occurrence in the pediatric population. Only a few cases are described in the literature. One study in Taiwan showed that $81 \%$ of spontaneous PM was preceded by cough, and $50 \%$ of the patients with PM had asthma [1]. The main trigger factors in another study, analyzing the etiologies of spontaneous PM in children, were infections (43.2\%) and asthma (21\%), and only one child had FB aspiration [6]. In a review, Gasser et al. reported that the most frequent comorbidity in children was asthma (22.2\%), and the most common trigger factors were bronchospasm (49\%), cough (45.6\%), vomiting (10.3\%), and FB aspiration (8.3\%) [5]. In a retrospective review of 155 children with FB aspiration, 9 patients (5.8\%) had PM [7]. At the Children's Medical Center in China, over a period of 10 years, no cases of spontaneous PM were found to be associated with FB aspiration [8]. In another review, performed in the United States, among 126 children with FB aspiration, only one case with PM was reported [2].
Even if the most common causes of spontaneous PM and SCE are asthma and infections, the possibility of FB aspiration should be considered, especially in patients under 3 years old, owing to multiple physiological, environmental, and developmental factors [9]. In a retrospective review of 55 children, Saliba et al. found that children with asthma were significantly more likely than children without asthma to have a negative bronchoscopy result. Their study concluded that a conservative approach cannot be justified in children with suspected asthma with possible FB aspiration [10]. Recently, a similar case report about three children with asthma was reported. The three children presenting with PM and SCE were treated initially as having acute asthma exacerbations, but they were found to have FB aspiration. These children were aged 16, 20, and 21 months. Through these cases, the authors highlight that physicians must remain vigilant and look for comorbidities in cases of asthma exacerbation, especially for FB aspiration, which should be excluded. Thus, a very high index of suspicion should be taken into account in cases with insufficient response to conventional asthma treatment and localized clinical signs [11]. Mohd Ariff et al. reported a case of an undiagnosed chicken meat aspiration in a 12-year-old boy with traumatic brain injury and a history of asthma. Their article emphasized that FB aspiration needs to be considered as one of the causes of postintubation difficult-to-ventilate scenarios. Prompt diagnosis and bronchoscope-assisted removal of FB is essential in reducing morbidity and mortality [12]. Note that the combination of acute asthma exacerbation and FB aspiration creates a pathophysiological condition that predisposes the appearance of PM, SCE, or even a pneumothorax (valve phenomenon). Because our patient was diagnosed with asthma and followed as such and had no recent history of FB aspiration as reported by the parents, he was initially treated as having an acute asthma exacerbation complicated by PM. There was no clinical or radiological evidence of FB aspiration. Owing to insufficient clinical improvement with the appropriate treatment, however, the possibility of a differential diagnosis, especially that of FB aspiration, was considered. So, a rigid bronchoscopy (size 5.0) was safely performed, and the FB was successfully removed.

Spontaneous PM generally resolves spontaneously within a few days. It requires a conservative treatment consisting of simple clinical monitoring, rest, and analgesics. Underlying disorders should also always be identified and treated $[4,13]$. Cases of idiopathic SPM require diagnostic pulmonary function tests after the acute episode to establish whether the child has asthma [13]. The FB aspiration results in significant morbidity and mortality in children. Acute and chronic complications seem to occur in almost $15 \%$ of patients [14]. Early diagnosis and treatment are of utmost importance to prevent life-threatening and 
long-term complications. Close communication between the medical team (anesthesiologist, bronchoscopist, pediatrician, and assistants) is essential. Bronchoscopy is generally considered the gold standard of diagnosis. Rigid bronchoscopy under general anesthesia must be performed urgently, and the patient should be observed carefully. Supportive care should be administered with intravenous steroids and reflux medications [9]. But physicians must be aware of the risk of worsening bronchospasm in children with asthma who undergo bronchoscopy [11]. It has been shown that bronchoscopy under general anesthesia can be performed safely in children with difficult asthma if it is performed by experienced personnel [15]. Virtual bronchoscopy has also been proposed to minimize the risks of rigid bronchoscopy by shortening the operative time and providing information about the localization and size of the FB [16].

\section{Conclusions}

Even if asthma exacerbation represents the most common cause of PM and SCE, the possibility of FB aspiration should always and carefully be considered in children with asthma as an important differential diagnosis, even in the absence of a history of FB aspiration.

\section{Abbreviations}

FB: Foreign body; PM: Pneumomediastinum; SCE: Subcutaneous emphysema

\section{Acknowledgements}

The authors want to acknowledge warmly Mrs. Nezha Haimeur, physician in the Department of Anesthesia and Critical Care of Mohammed VI University Hospital of Marrakesh, for her close cooperation and all the efforts made for the best management of children.

\section{Funding}

Not applicable.

Availability of data and materials

Not applicable.

\section{Authors' contributions}

$M B$ and $W L$ were major contributors in writing the manuscript. $\mathrm{HN}$ and $\mathrm{NH}$ analyzed and corrected the details of the article. All authors read and approved the final manuscript

\section{Ethics approval and consent to participate}

Not applicable (the anonymity and confidentiality of the patient have been respected).

\section{Consent for publication}

Written informed consent was obtained from the patient's legal guardian for publication of this case report and any accompanying images. A copy of the written consent is available for review by the Editor-in-Chief of this journal.

\section{Competing interests}

The authors declare that they have no competing interests.

\section{Publisher's Note}

Springer Nature remains neutral with regard to jurisdictional claims in published maps and institutional affiliations.

\section{Author details}

'Department of Paediatric Emergency, UHC Mohamed VI, Cadi Ayyad University, Faculty of medicine and pharmacy, PO Box: 7010, Sidi Abbad Street, 40000 Marrakech, Morocco. ${ }^{2}$ Department of ORL, UHC Mohamed VI, Cadi Ayyad University, Marrakech, Morocco. ${ }^{3}$ Department of Anesthesia and Critical Care, UHC Mohamed VI, Cadi Ayyad University, Marrakech, Morocco.

Received: 6 November 2018 Accepted: 9 April 2019

Published online: 26 May 2019

\section{References}

1. Chiu CY, Wong KS, Yao TC, Huang JL. Asthmatic versus non-asthmatic spontaneous pneumomediastinum in children. Asian Pac J Allergy Immunol. 2005;23(1):19-22.

2. Damore DT, Dayan PS. Medical causes of pneumomediastinum in children. Clin Pediatr (Phila). 2001;40(2):87-91.

3. Bullaro FM, Bartoletti SC. Spontaneous pneumomediastinum in children: a literature review. Emerg Care. 2007;23(1):28-30.

4. Tortajada-Girbés M, Moreno-Prat M, Ainsa-Laguna D, Mas S. Spontaneous pneumomediastinum and subcutaneous emphysema as a complication of asthma in children: case report and literature review. Ther Adv Respir Dis. 2016:10(5):402-9.

5. Gasser CR, Pellaton R, Rochat CP. Pediatric spontaneous pneumomediastinum: narrative literature review. Pediatr Emerg Care. 2017; 33(5):370-4

6. Lee CY, Wu CC, Lin CY. Etiologies of spontaneous pneumomediastinum in children in middle Taiwan. Pediatr Pulmonol. 2010;45(9):869-73.

7. Burton EM, Riggs WJ, Kaufman RA, Houston CS. Pneumomediastinum caused by foreign body aspiration in children. Pediatr Radiol. 1989;20(1-2): $45-7$.

8. Lee CY, Wu CC, Lin CY. Etiologies of spontaneous pneumomediastinum in children of different ages. Pediatr Neonatol. 2009;50(5):190-5.

9. Hu M, Green R, Gungor A. Pneumomediastinum and subcutaneous emphysema from bronchial foreign body aspiration. Am J Otolaryngol. 2013;34(1):85-8.

10. Saliba J, Mijovic T, Daniel S, Nguyen LH, Manoukian J. Asthma: the great imitator in foreign body aspiration? J Otolaryngol Head Neck Surg. 2012; 41(3):200-6.

11. Nimrey-Atrash N, Bentur L, Elias N. Subcutaneous emphysema and pneumomediastinum due to foreign body aspiration in children with asthma. Pediatr Pulmonol. 2012;47:88-90.

12. Mohd Ariff NA, Mazlan MZ, Mat Hassan ME, Seevaunnamtum PA, Wan Muhd Shukeri WF, Nik Mohamad NA, et al. Undiagnosed chicken meat aspiration as a cause of difficult-to-ventilate in a boy with traumatic brain injury. Respir Med Case Rep. 2018;23:93-5.

13. Chalumeau M, Le Clainche L, Sayeg N, Sannier N, Michel JL, Marianowski R, et al. Spontaneous pneumomediastinum in children. Pediatr Pulmonol. 2001;31(1):67-75.

14. Foltran F, Ballali S, Passali FM, Kern E, Morra B, Passali GC, et al. Foreign bodies in the airways: a meta-analysis of published papers. Int J Pediatr Otorhinolaryngol. 2012;76(Suppl 1):S12-9.

15. Payne D, McKenzie SA, Stacey S, Misra D, Haxby E, Bush A. Safety and ethics of bronchoscopy and endobronchial biopsy in difficult asthma. Arch Dis Child. 2001;84:423-6.

16. Cevizci N, Dokucu Al, Baskin D, Karadağ CA, Sever N, Yalçin M, et al. Virtual bronchoscopy as a dynamic modality in the diagnosis and treatment of suspected foreign body aspiration. Eur J Pediatr Surg. 2008;18(6):398-401.

Ready to submit your research? Choose BMC and benefit from:

- fast, convenient online submission

- thorough peer review by experienced researchers in your field

- rapid publication on acceptance

- support for research data, including large and complex data types

- gold Open Access which fosters wider collaboration and increased citations

- maximum visibility for your research: over $100 \mathrm{M}$ website views per year

At BMC, research is always in progress.

Learn more biomedcentral.com/submission 